\title{
Pesquisa de sujidades e matérias estranhas em mel de abelhas (Apis mellifera L.)
}

\author{
Research of dirtiness and strange materials in bee (Apis mellifera L.) honey
}

Ricardo Silva de SOUSA ${ }^{1}$, Júlia Geracila de Mello e CARNEIRO ${ }^{2 *}$

\section{Resumo}

O mel de abelhas é um produto que pode ter a sua qualidade comprometida devido à sua forma de obtenção e manipulação. Coletaram-se 52 amostras de mel produzido no estado do Piauí (sendo 25 amostras de Picos, 1 de São Miguel do Tapuio, 2 de Pio IX, 9 de Itainópolis, 5 de São Raimundo Nonato, 5 de Simplício Mendes e 5 de Piripiri), que foram encaminhadas ao Laboratório de Análises Físico-químicas do Núcleo de Estudos, Pesquisa e Processamento de Alimentos - NUEPPA do Centro de Ciências Agrárias - CCA, da Universidade Federal do Piauí - UFPI, para análise da presença de sujidades e matérias estranhas segundo as metodologias I e II recomendadas por Santa Catarina (1985). Das amostras analisadas pelas metodologias I e II, 65,38 e 30,77\%, respectivamente, não atendiam aos aspectos macroscópico e microscópico e aos padrões de identidade e qualidade do mel (BRASIL, 2001), por apresentarem sujidades e matérias estranhas, tais como: insetos, larvas, ácaros, pêlos humanos e de roedores, traças, dentre outras.

Palavras-chave: mel de abelhas; microscopia; sujidades.

\begin{abstract}
Honey from bees is a product that can have its quality reduced due to its form of attainment and manipulation. Fifty-two samples of honeys produced in the State of Piauí (being 25 from Picos, 1 from São Miguel do Tapuio, 2 from Pio IX, 9 from Itainópolis, 5 from São Raimundo Nonato, 5 from Simplício Mendes and 5 from Piripiri) were collected. They were sent to the Laboratory of Physical and Chemical Analyses of the Nucleus of Studies, Research and Processing of Foods - NUEPPA of the Center of Agrarian Sciences - CCA of the Federal University of Piauí - UFPI, for analysis of the presence of dirtiness and strange materials, according to methodologies I and II recommended by SANTA CATARINA (1985). Of the samples analyzed by methodologies I and II, 65.38 and 30.77\%, respectively, did not attend the macroscopic and microscopic aspects and the identity and quality standards for honeyl, due to the presence of dirtiness and strange materials, such as insects, larvae, mites, human and rodent hairs, moths, amongst others.

Keywords: bee honey; microscopy; dirtiness.
\end{abstract}

\section{Introdução}

Entende-se por mel o produto alimentício produzido pelas abelhas melíferas a partir do néctar das flores ou das secreções procedentes de partes vivas das plantas ou mesmo de secreções de insetos sugadores de plantas que ficam sobre partes vivas das mesmas, que as abelhas recolhem, transformam, combinam com substâncias específicas próprias, armazenam e deixam madurar nos favos da colméia (BRASIL, 2001).

A tecnologia do mel começa quando o apicultor retira o favo da colméia, e a partir daí efetiva a colheita e o respectivo processamento dentro de normas técnicas e altamente higiênicas, para que o produto alcance o consumidor com todas as suas qualidades essenciais, sem outras interferências prejudiciais (WIESE, 1985).

O Piauí é um dos poucos estados do país que reúne as condições de recursos naturais e de exploração agrícola ideais para produção de mel, já que esta deve ser completamente isenta de contaminações por produtos químicos, microrganismos e partículas sólidas transportadas pelo ar, pelos manipuladores da colheita e do processamento (VILELA, 2000).
Com o incremento do consumo de produtos naturais, o mel tem sido util izado e comercializado mais intensamente, de modo que aumentam também as possibilidades de fraudes, adulterações e manipulação inadequada (CANO et al., 1992).

Os padrões de identidade e qualidade do mel (BRASIL, 2001) requerem, quanto aos aspectos macroscópico e microscópico, que o produto esteja isento de substâncias estranhas de qualquer natureza, tais como: insetos, larvas, grãos de areia e outros.

Os insetos e os ácaros, além de depositarem suas dejeções sobre os alimentos causando doenças por fungos, bactérias, vírus, protozoários e helmintos, também podem contaminar os produtos com microrganismos que se encontram aderidos ao seu corpo e às suas pernas. Além disso, os ácaros podem desencadear processos alérgicos em indivíduos susceptíveis, quando ingeridos com alimentos (CORREIA; RONCADA, 2002).

A pesquisa objetivou estabelecer e divulgar o perfil microscópico da qualidade do mel de abelhas produzido no estado do

Recebido para publicação em 3/5/2006

Aceito para publicação em 18/12/2007 (001739)

${ }^{1}$ Centro de Ciências Agrárias, Universidade Federal do Piauí - UFPI

${ }^{2}$ Departamento de Fitotecnia - DF, Centro de Ciências Agrárias - CCA, Universidade Federal do Piauí - UFPI, CEP 64049-550, Teresina - PI, Brasil, E-mail: jgmello@ufpi.br

${ }^{*}$ A quem a correspondência deve ser enviada 
Piauí, tendo em vista que na literatura existem poucos trabalhos com essa finalidade, bem como estimular os apicultores na realização de um trabalho íntegro e confiável, assegurando a qualidade requerida para comercialização interna e externa do produto.

\section{Material e métodos}

As amostras foram analisadas microscopicamente para pesquisa de sujidades e matérias estranhas, através de duas metodologias (metodologia I: diluição em água, filtração em Büchner e leitura em lupa com aumento de 10 e 20x, e metodologia II: diluição da amostra em água, seguida de centrifugação e análise do sedimento entre lâmina e lamínula ao microscópio) propostas por Santa Catarina (1985), 52 amostras de mel de abelhas produzidas no estado do Piauí, sendo 25 de Picos, 1 de São Miguel do Tapuio, 2 de Pio IX, 9 de Itainópolis, 5 de São Raimundo Nonato, 5 de Piripiri e 5 de Simplício Mendes, que depois de coletadas apropriadamente foram encaminhadas ao Laboratório de Análises Físico-químicas do Núcleo de Estudos, Pesquisa e Processamento de Alimentos (NUEPPA) do Centro de Ciências Agrárias (CCA) da Universidade Federal do Piauí (UFPI).

A identificação dos elementos encontrados no mel foi registrada através de fotografias obtidas por uma câmera (modelo C-35 Olympus) acoplada a um microscópio de microfotografia triocular (modelo CBAK Olympus), do Laboratório de Sanidade Animal (LASAN/CCA/UFPI).

\section{Resultados e discussão}

A Figura 1 e a Tabela 1 trazem os tipos de ocorrências de sujidades e matérias estranhas isoladas e identificadas nas 52 amostras analisadas. Utilizando-se a metodologia I, detectouse a presença de ácaros em $23,53 \%$ das amostras; foram encontrados fragmentos de insetos em $67,65 \%$ delas; e verificou-se a presença de larvas em $52,94 \%$ do total de amostras em desacordo. Foram ainda encontrados pêlos humanos ( 1 amostra) e de roedores ( 1 amostra), representando a porcentagem de 5,88\%; e a ocorrência de traças em duas amostras (5,88\%). Diante da legislação em vigor (BRASIL, 2001), 65,38\% das amostras analisadas (34) foram consideradas fora dos padrões de identidade e qualidade do mel. Quando analisadas pela metodologia II, $43,75 \%$ continham larvas, $12,5 \%$ ácaros e $62,5 \%$ fragmentos de insetos, portanto, $30,77 \%$ delas (16) estavam fora dos padrões exigidos pela legislação vigente. Nas análises realizadas pelos dois métodos, todas as amostras apresentavam pêlos de abelhas e pólen, e algumas apresentavam própolis e cera.

\section{Conclusão}

A análise microscópica das amostras de mel, considerandose respectivamente as metodologias I e II, revela que 34,62 e $69,23 \%$ das amostras foram aprovadas, apontando o melhor desempenho da metodologia I na detecção das sujidades e matérias estranhas.
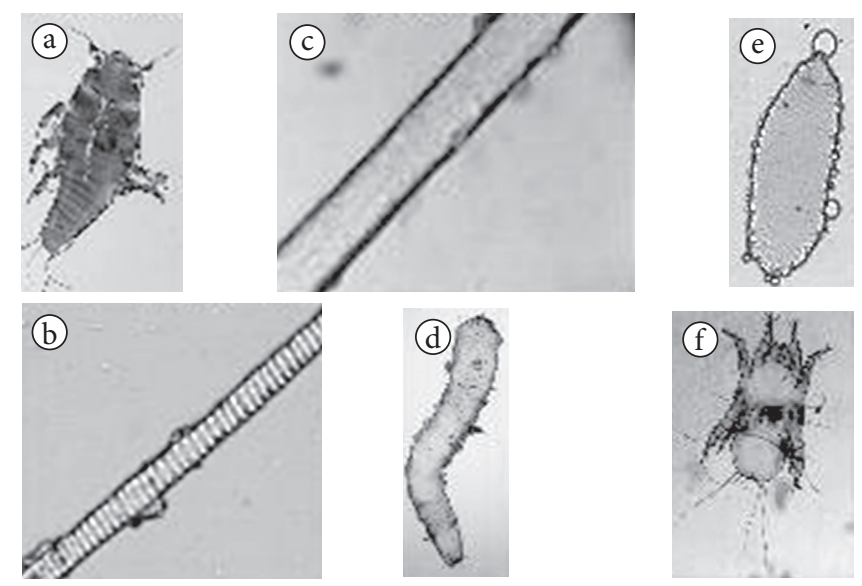

Figura 1. Ilustração das principais ocorrências: a) traça; b) pêlo de roedor; c) pêlo humano; d) e e) larvas; e f) ácaro.

Tabela 1. Porcentagem de reprovação e tipos de sujidades encontradas nas amostras de mel de abelhas reprovadas pela metodologia I (34) e II (16). Teresina, 2004.

\begin{tabular}{lcc}
\hline \multicolumn{1}{c}{ Ocorrências } & Metodologia I (\%) & Metodologia II (\%) \\
\hline Ácaros & 23,53 & 12,5 \\
Larvas & 52,94 & 43,75 \\
Fragmentos de insetos & 67,65 & 62,5 \\
Pêlo humano & 2,94 & - \\
Pêlo de roedor & 2,94 & - \\
Traças & 5,88 & - \\
\hline
\end{tabular}

\section{Agradecimentos}

Os autores agradecem ao CNPq pelo apoio financeiro através da concessão da bolsa de iniciação científica.

\section{Referências bibliográficas}

BRASIL. Ministério da Agricultura e do Abastecimento. Instrução Normativa ${ }^{\circ}$ 11, de 20/10/2000, Padrão de Identidade e Qualidade do Mel. DOU de 23/01/2001, Seção 1, p. 18-23. Disponível em: $<$ http://www.agricultura.gov.br//das/dispoa/instrunormativa11. htm >. Acesso em: 30 mar. 2001.

CANO, C. B. et al. Mel: Fraudes e condições sanitárias. Rev. Inst. Adolfo Lutz, v. 52, n. 1/2, p. 1-4, 1992.

CORREIA, M.; RONCADA, M. J. Padronização de métodos e quantificação de matérias estranhas e filamentos micelianos. I. Doces de frutas em pasta. Rev. Inst. Adolfo Lutz, v. 62, n. 2, p. 85-90, 2002.

SANTA CATARINA (Estado). Secretaria de Saúde. Departamento Autônomo de Saúde Pública. Laboratório Central de Saúde Pública. Normas de Análises Bromatológicas. Análise de mel e Cera. v. II. Florianópolis: Divisão de Bromatologia, 1985.

VILELA, S. L. O. (Org.). Cadeia produtiva do mel no estado do Piauí. Teresina: Embrapa Meio - Norte, 2000. 121 p. il.

WIESE, H. Nova Apicultura, 6a ed. Porto Alegre: Agropecuária, 1985. $493 \mathrm{p}$. 